\title{
Terahertz spectroscopy of hydrogen sulfide
}

\author{
Ala'a A. A. Azzam, Sergei N. Yurchenko, Jonathan Tennyson \\ Department of Physics and Astronomy, University College London, London, WC1E 6BT, UK \\ Marie-Aline Martin-Drumel* and Olivier Pirali \\ CNRS, UMR 8214, Institut des Sciences Moléculaires d'Orsay, Université Paris Sud XI, Orsay, F-91405 Orsay, \\ France and Synchrotron SOLEIL, AILES beamline, F-91192 Gif-Sur-Yvette, France
}

\begin{abstract}
Pure rotational transitions of hydrogen sulfide $\left(\mathrm{H}_{2} \mathrm{~S}\right)$ in its ground and first excited vibrational states have been recorded at room temperature. The spectrum comprises an average of 1020 scans at $0.005 \mathrm{~cm}^{-1}$ resolution recorded in the region 45 to $360 \mathrm{~cm}^{-1}(1.4$ to $10.5 \mathrm{THz})$ with a globar continuum source using a Fourier transform spectrometer located at the AILES beamline of the SOLEIL synchrotron. Over 2000 rotational lines have been detected belonging to ground vibrational state transitions of the four isotopologues $\mathrm{H}_{2}{ }^{32} \mathrm{~S}, \mathrm{H}_{2}{ }^{33} \mathrm{~S}, \mathrm{H}_{2}{ }^{34} \mathrm{~S}$, and $\mathrm{H}_{2}{ }^{36} \mathrm{~S}$ observed in natural abundance. $65 \%$ of these lines are recorded and assigned for the first time, sampling levels as high as $J=26$ and $K_{a}=17$ for $\mathrm{H}_{2}{ }^{32} \mathrm{~S} .320$ pure rotational transitions of $\mathrm{H}_{2}{ }^{32} \mathrm{~S}$ in its first excited bending vibrational state are recorded and analysed for the first time and 86 transitions for $\mathrm{H}_{2}{ }^{34} \mathrm{~S}$, where some of these transitions belong to new experimental energy levels. Rotational constants have been fitted for all of the isotopologues in both vibrational states using a standard effective Hamiltonian approach. Comprehensive comparisons are made with previously available data as well as the data available in HITRAN, CDMS, and JPL databases. The 91 transitions assigned to $\mathrm{H}_{2}{ }^{36} \mathrm{~S}$ give the first proper characterization of its rotational spectrum.
\end{abstract}

Keywords: Hydrogen sulfide, line assignments, atmospheric physics, planetary atmospheres PACS: 33.20.Ea, 33.20.Vq

\footnotetext{
*Present address: Laboratoire de Physico-Chimie de l'Atmosphère, EA 4493, Université du Littotal Côte d'Opale, F-59140 Dunkerque, France

Preprint submitted to Journal of Quantitative Spectroscopy \& Radiative Transfer

May 28, 2013
} 


\section{Introduction}

Hydrogen sulfide $\left(\mathrm{H}_{2} \mathrm{~S}\right)$ is produced naturally in volcanoes [1] and is a byproduct of human activity such as water treatment processes [2]; it is therefore a trace species in the Earth's atmosphere. It is known to be more abundant in the atmospheres of solar system gas giants [3] and it thought to be important for the sulfur chemistry of extra-solar planets [4]. Indeed it is also found in the atmospheres of cool stars and is the dominant sulfur-bearing gas-phase species in substellar objects such as brown dwarfs [3]. $\mathrm{H}_{2} \mathrm{~S}$ has long been known to be present in interstellar clouds in our galaxy [5] and has been also observed in starburst galaxies [6]. Its role in shocks and star formation regions is thought to be of particular importance [7]. Modern astronomical telescopes such as Herschel, SOFIA and ALMA have allowed astronomers to observe species such as $\mathrm{H}_{2} \mathrm{~S}$ at $\mathrm{THz}$ frequencies for the first time [8], thus opening a window on higher-lying rotational levels for this species.

$\mathrm{H}_{2} \mathrm{~S}$ is a light nonrigid molecule width $\mathrm{C}_{2 \mathrm{v}}$ symmetry. This molecule has three vibrational modes: two overlapped stretching; symmetric $\left(\nu_{1}\right)$ and asymmetric $\left(\nu_{3}\right)$ respectively at 2615 and $2626 \mathrm{~cm}^{-1}$, and one bending $\left(\nu_{2}\right)$ at $1183 \mathrm{~cm}^{-1} . \mathrm{H}_{2} \mathrm{~S}$ is a near oblate asymmetric top rotor with $\kappa=0.52$. Four sulfur isotopes are stable: ${ }^{32} \mathrm{~S},{ }^{33} \mathrm{~S},{ }^{34} \mathrm{~S}$, and ${ }^{36} \mathrm{~S}$ with natural abundances of $95.02 \%, 0.75 \%, 4.21 \%$ and $0.02 \%$ respectively.

Since the work of Burrus et al. [9], numerous studies have been performed of $\mathrm{H}_{2} \mathrm{~S}$ rotational transitions in the ground vibrational state in the region up to about $9.3 \mathrm{THz}\left(310 \mathrm{~cm}^{-1}\right)$. In the microwave region, 82 lines have been detected for the main isotopologue $\left(\mathrm{H}_{2}{ }^{32} \mathrm{~S}\right)$ [9-15], 40 transitions for $\mathrm{H}_{2}{ }^{34} \mathrm{~S}[9,10,12,16], 155$ transitions for $\mathrm{H}_{2}{ }^{33} \mathrm{~S}$ with hyperfine splitting due to ${ }^{33} \mathrm{~S}$ nucleus [9, 16], and 3 experimental transitions for $\mathrm{H}_{2}{ }^{36} \mathrm{~S}$ as well [16]. In the far infrared (FIR), 443 observed transitions have been reported for $\mathrm{H}_{2}{ }^{32} \mathrm{~S}$ [15, 17-19], 71 transitions for $\mathrm{H}_{2}{ }^{33} \mathrm{~S}$ [18], and 173 transitions for $\mathrm{H}_{2}{ }^{34} \mathrm{~S}$ [18].

Particularly important for this work are the measurements by Flaud et al. [18], who probed the region below $9.3 \mathrm{THz}$, and of Yamada and Klee [19], who made measurements in the same region. Frequencies from these two works in addition to the available experimental microwave 
data, and effective Hamiltonian fits to them, provide the rotational spectra used in recent editions of HITRAN [20, 21] and JPL [22] databases, respectively. However rotational frequencies beyond $10 \mathrm{THz}$ are estimated by extrapolating these formula. In CDMS database [23, 24], the pure rotational transitions have been calculated using all the available measured transitions in the microwave and (FIR) region. We note that the higher rotational states of $\mathrm{H}_{2} \mathrm{~S}$ are also of interest theoretically [25].

Many other studies have been performed in order to detect the absorption transitions of $\mathrm{H}_{2} \mathrm{~S}$ molecule and its isotopologues $\left(\mathrm{H}_{2}{ }^{33} \mathrm{~S}\right.$ and $\left.\mathrm{H}_{2}{ }^{34} \mathrm{~S}\right)$ in its fundamental, hot, and combination vibrational bands covering the spectrum range up to $16500 \mathrm{~cm}^{-1}$. The most important for this work are the transitions in the fundamental bending mode $\left(\nu_{2}\right)$ [26-29]. Among these studies, Ulenikov et al. [29] reported the most accurate experimental upper state energy levels in $\nu_{2}$ band for $\mathrm{H}_{2}{ }^{32} \mathrm{~S}, \mathrm{H}_{2}{ }^{33} \mathrm{~S}$, and $\mathrm{H}_{2}{ }^{34} \mathrm{~S}$.

In this work we present new experimental measurements of the spectrum of hydrogen sulfide in the region $1.4-10.5 \mathrm{THz}\left(45-360 \mathrm{~cm}^{-1}\right)$. This work is a byproduct of our work in order to produce a complete hot line list of $\mathrm{H}_{2} \mathrm{~S}$ [30]. The following section gives experimental details. Section 3 presents the analysis of our new frequencies. In Section 4 a comprehensive comparison with the previous measurements is presented.

\section{Experiments}

The Fourier transform FIR absorption spectrum of gas phase $\mathrm{H}_{2} \mathrm{~S}$ in natural abundance was recorded using a globar source available on the Bruker IFS125 interferometer of the AILES beamline at the SOLEIL synchrotron [31]. A resolution of $0.005 \mathrm{~cm}^{-1}$ was used to record the spectrum in the spectral range $45-360 \mathrm{~cm}^{-1}$. A pressure of $0.16 \mathrm{mbar}$ of $\mathrm{H}_{2} \mathrm{~S}$ was injected in a room-temperature White-type cell aligned for an optical path length of $150 \mathrm{~m}$. The interferometer was pumped to a pressure below $10^{-4}$ mbar using a turbomolecular pump; two polypropylene windows were used to separate the interferometer from the absorption cell. The resulting spectrum is the coaddition of 1020 scans (about 12 hours of acquisition time). Fig- 
ure 1 shows an overview of the recorded spectrum, while Figure 2 gives an illustrative region containing newly observed lines.

Spectral calibration was performed using the residual water transitions and the accurate transition frequencies of Refs. [32] and [33]. A calibration curve was prepared to facilitate correction of the recorded frequencies for $\mathrm{H}_{2} \mathrm{~S}$. Figure 3 shows the dispersion of the water transitions before and after the calibration. The accuracy of the line position is thus estimated to be 0.0005 $\mathrm{cm}^{-1}$.

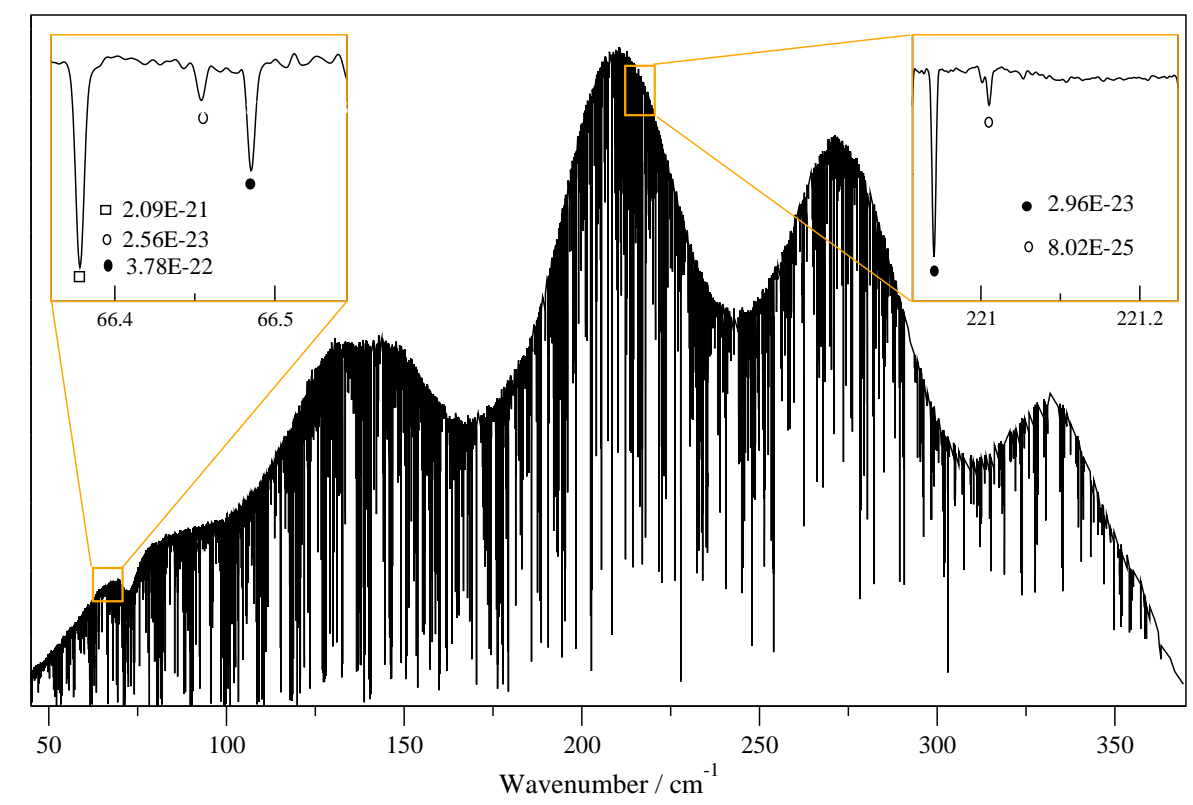

Figure 1: Room temperature absorption spectrum of $\mathrm{H}_{2} \mathrm{~S}$ recorded at AILES beamline. The insets illustrate detection of different line intensities for two sample regions of the spectrum. The numbers next to the symbols give the intensities of the lines in $\mathrm{cm}^{-1} /\left(\right.$ molecule $\left.\times \mathrm{cm}^{-2}\right)$ according to HITRAN [21].

\section{Spectral analysis}

Lines for $\mathrm{H}_{2} \mathrm{~S}$ molecule with intensities above $10^{-25} \mathrm{~cm}^{-1} /\left(\right.$ molecule $\left.\times \mathrm{cm}^{-2}\right)$ were detected for the region above $80 \mathrm{~cm}^{-1}$. In the region below $50 \mathrm{~cm}^{-1}$ only lines with intensity above about $10^{-23} \mathrm{~cm}^{-1} /\left(\right.$ molecule $\left.\times \mathrm{cm}^{-2}\right)$ were detected as a consequence of the nature of the spectrum 


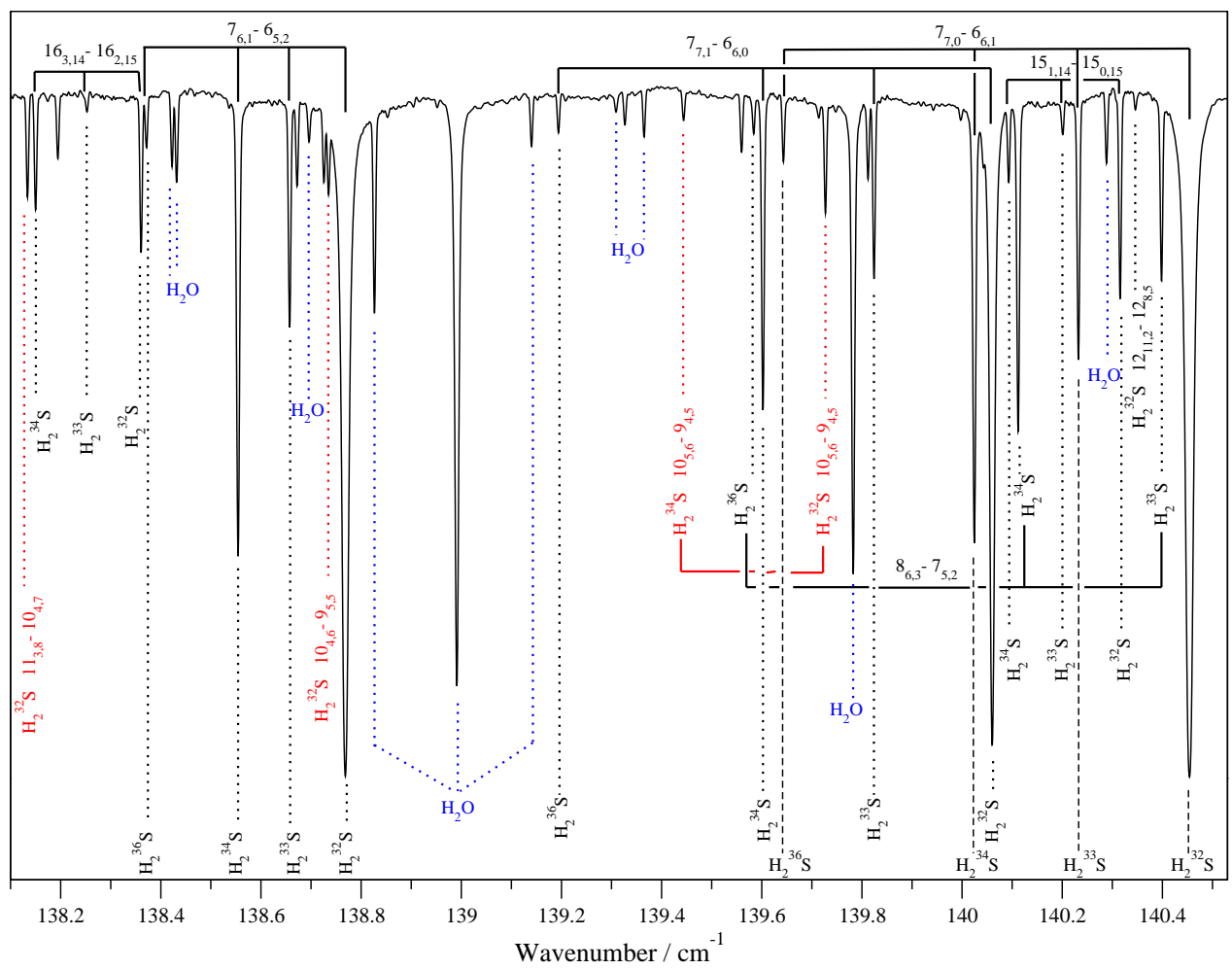

Figure 2: A portion of the absorption spectrum of $\mathrm{H}_{2} \mathrm{~S}$ recorded at SOLEIL, showing some rotational transitions in both ground and bending vibrational states $v_{2}=1$. The pure rotational transitions of the vibrational bending state $v_{2}=1$ are illustrated in red color.

obtained from the blackbody radiator: the low intensity of the light leads to a limited signalto-noise ratio which fast decreases below $50 \mathrm{~cm}^{-1}$ as seen in Figure 1. Examples of rge line detections with different intensities in the different regions of the spectrum are given in the same figure.

The absorption spectrum was analysed manually by matching lines with the available data in the HITRAN database [21] and the CDMS database [23, 24] for the main isotopologue for the vibrational ground state transitions. While for $\mathrm{H}_{2}{ }^{33} \mathrm{~S}$ and $\mathrm{H}_{2}{ }^{34} \mathrm{~S}$ in their vibrational ground state, the HITRAN database was used. For the $\mathrm{H}_{2}{ }^{36} \mathrm{~S}$ isotopologue, many transitions were identified and assigned manually by extrapolating the line positions of the three other isotopologues for given quantum numbers, see Figure 2. The pure rotational transitions of the vibrational 


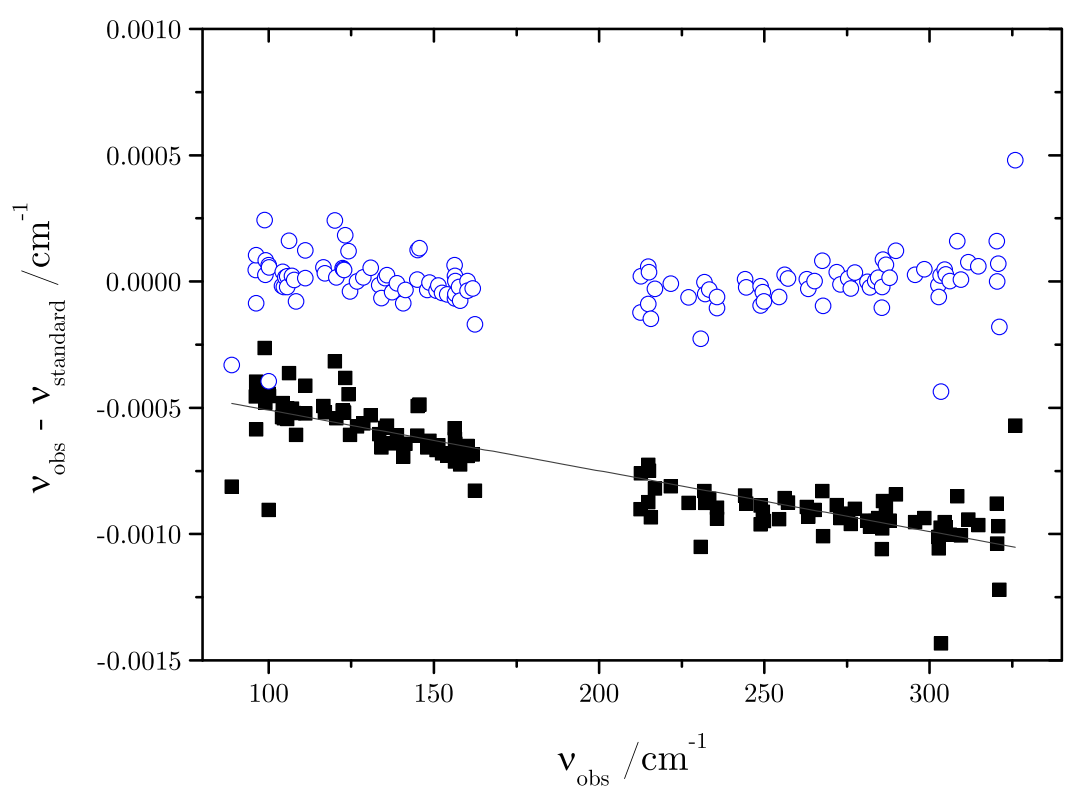

Figure 3: Calibration of the FIR Fourier transform spectrum recorded in this work. Water line positions before calibration ( $\mathbf{\square}$ ) and after calibration (o) based in the accurate water line positions of Refs. [32] and [33]. The line equation in $\mathrm{cm}^{-1}$ is $d=-2.40(12) \nu-2.69(26)$, where $d$ is the dispersion and $\nu$ is the transition frequency. The standard deviation after calibration is $1.05 \times 10^{-4} \mathrm{~cm}^{-1}$.

state $v_{2}=1$ of $\mathrm{H}_{2}{ }^{32} \mathrm{~S}$ were initially assigned using a variational line list calculated using the DVR3D variational nuclear motion program [34]. This line list will be published elsewhere [30]. Experimental upper energy levels belong to $\nu_{2}$ band given by Ulenikov et al. [29] were used to calculate the pure rotational transitions in the $v_{2}=1$ state for $\mathrm{H}_{2}{ }^{32} \mathrm{~S}$ and $\mathrm{H}_{2}{ }^{34} \mathrm{~S}$. These calculated transitions were used to confirm the assignments for $\mathrm{H}_{2}{ }^{32} \mathrm{~S}$ and to identify rotational transitions for $\mathrm{H}_{2}{ }^{34} \mathrm{~S}$.

Pickett's program CALPGM [35] was used to fit the observed spectra for each of the four isotopologues in both states of this molecule studied in this work. Table 1 summarises the number of the fitted parameters and the number of the spectral lines used in the fit for each isotopologues in both vibrational states. For $\mathrm{H}_{2}{ }^{32} \mathrm{~S}$ in the ground vibrational state, the 926 newly-recorded lines were combined with 462 lines of Helminger et al. [13], Belov et al. [15], Yamada and Klee 
[19]. The resulting fit parameters were used to predict 2919 transitions for $\mathrm{H}_{2}{ }^{32} \mathrm{~S}$ in the ground vibrational state up to $J=30$ and $K_{a}=20.576$ lines of our measurements were combined with 40 lines Saleck et al. [16], Huiszoon and Dymanus [36] available in the literature for $\mathrm{H}_{2}{ }^{34} \mathrm{~S}$ to fit 41 parameters. Using the fitted parameters, a pure rotational spectrum was predicted up to around $600 \mathrm{~cm}^{-1}$. This predicted spectrum contains 2554 lines with $J$ up to 28 and $K_{a}$ up to 19. For $\mathrm{H}_{2}{ }^{32} \mathrm{~S}, 320$ newly-recorded pure rotational transitions of the vibrational state $v_{2}=1$ were used in the fittings together with 743 rotational transitions calculated from the $\nu_{2}$ experimental energy levels of Ulenikov et al. [29]. For $\mathrm{H}_{2}{ }^{34} \mathrm{~S}$, the 86 newly-recorded transitions were combined with 240 rotational transitions calculated from the $\nu_{2}$ experimental energy levels from the same paper, see Table 2. For $\mathrm{H}_{2}{ }^{33} \mathrm{~S}, 433$ of our measured lines were used together with 155 microwave lines measured by Saleck et al. [16] to fit 31 rotational constants and 3 electric quadrupole hyperfine constants for the ${ }^{33} \mathrm{~S}$ nucleus. The predicted spectrum was calculated using the fitted rotational constants only, i.e. neglecting the hyperfine structure. This spectrum contains 2471 lines with $J$ up to 32 and $K_{a}$ up to 20 . Because of the the lower abundance of the isotopologue $\mathrm{H}_{2}{ }^{36} \mathrm{~S}$, we were able to detect only 91 transitions, with highest $J$ and $K_{a}$ values of 15 and 11 respectively. These transitions were combined with a single microwave line published by Saleck et al. [16] to fit 24 rotational parameters.

The presence of the $\mathrm{H}_{2} \mathrm{~S}$ ortho - para doublets with the 3 to 1 intensity ratio was taken into account in the line assignment process. A value of $\mu=0.9783 \mathrm{D}$ [37] for the permanent dipole moment was used in our intensity calculations. For $\mathrm{H}_{2}{ }^{32} \mathrm{~S}, \mathrm{H}_{2}{ }^{33} \mathrm{~S}$ and $\mathrm{H}_{2}{ }^{34} \mathrm{~S}$, the partition function values 503.07, 503.725 and 504.35 [38], respectively, were used in our calculations. For $\mathrm{H}_{2}{ }^{36} \mathrm{~S}$, the partition function $Q=506.51$ was calculated by the CALPGM program. For the intensities of the pure rotational transitions of $\mathrm{H}_{2}{ }^{32} \mathrm{~S}$ and $\mathrm{H}_{2}{ }^{34} \mathrm{~S}$ within their first excited vibrational states $v_{2}=1$, the vibrational band origins from Ref. [29] were used in order to correct the intensity produced by the CALPGM program as given by:

$$
I=a I_{\mathrm{CALPGM}} e^{-c_{2} E_{\mathrm{BO}} / T},
$$

where $a$ is the isotopologue abundance, $E_{\mathrm{BO}}$ is the band origin in $\mathrm{cm}^{-1}, c_{2}$ is the second radiation 
constant and $T$ is the temperature in $\mathrm{K}$.

The constants obtained from the fits are presented in Tables 3 and 4 . The predicted transitions of $\mathrm{H}_{2}{ }^{32} \mathrm{~S}$ and $\mathrm{H}_{2}{ }^{34} \mathrm{~S}$ in its ground and $v_{2}=1$ vibrational states, as well as these for $\mathrm{H}_{2}{ }^{33} \mathrm{~S}$ and $\mathrm{H}_{2}{ }^{36} \mathrm{~S}$ in their ground vibrational states, are given in the supplementary material.

\section{Results and Discussion}

In this work, more than 2400 lines are recorded for the four isotopologues of $\mathrm{H}_{2} \mathrm{~S}$ in the ground vibrational state, and for $\mathrm{H}_{2}{ }^{32} \mathrm{~S}$ and $\mathrm{H}_{2}{ }^{34} \mathrm{~S}$ in the first excited bending state. Table 1 summarises the measurements of the $\mathrm{H}_{2} \mathrm{~S}$ rotational spectra from this work and from previous studies. Detailed results for the rotational transitions of $\mathrm{H}_{2}{ }^{32} \mathrm{~S}$ and $\mathrm{H}_{2}{ }^{34} \mathrm{~S}$ in their ground and first excited bending state, as well as $\mathrm{H}_{2}{ }^{33} \mathrm{~S}$ and $\mathrm{H}_{2}{ }^{36} \mathrm{~S}$ in their ground states are given in the supplementary material. After a description of the available data used for comparison with this work, results will be detailed.

\subsection{Available data}

The line positions of the rotational band spectrum collected in HITRAN were originally obtained by Flaud et al. [18] in 1983, who recorded a hydrogen sulfide spectrum between 50 and $310 \mathrm{~cm}^{-1}$ with a Fourier transform spectrometer at a resolution of $0.005 \mathrm{~cm}^{-1}$. In this experiment the three isotopic species $\mathrm{H}_{2}{ }^{32} \mathrm{~S}, \mathrm{H}_{2}{ }^{33} \mathrm{~S}, \mathrm{H}_{2}{ }^{34} \mathrm{~S}$ were observed in natural abundance. Flaud et al. [18] have measured 631 lines in this region and combined them with 42 previously published microwave transitions in a least squares fit. Rotational constants for each isotopologue were calculated using the A-I ${ }^{r}$ representation of the Watson Hamiltonian. These constants were used to predict the positions of the absorption of the natural abundance hydrogen sulfide in the FIR region and intensities using $\mu=0.974 \mathrm{D}$ for the permanent dipole moment [10].

In 1994 Yamada and Klee [19] recorded a pure rotational spectrum for $\mathrm{H}_{2}{ }^{32} \mathrm{~S}$ in the FIR region using a Fourier transform infrared spectrometer. They detected more than 370 transitions in the region 30 to $260 \mathrm{~cm}^{-1}$ with a resolution of $0.0017 \mathrm{~cm}^{-1}$. These lines were combined with 


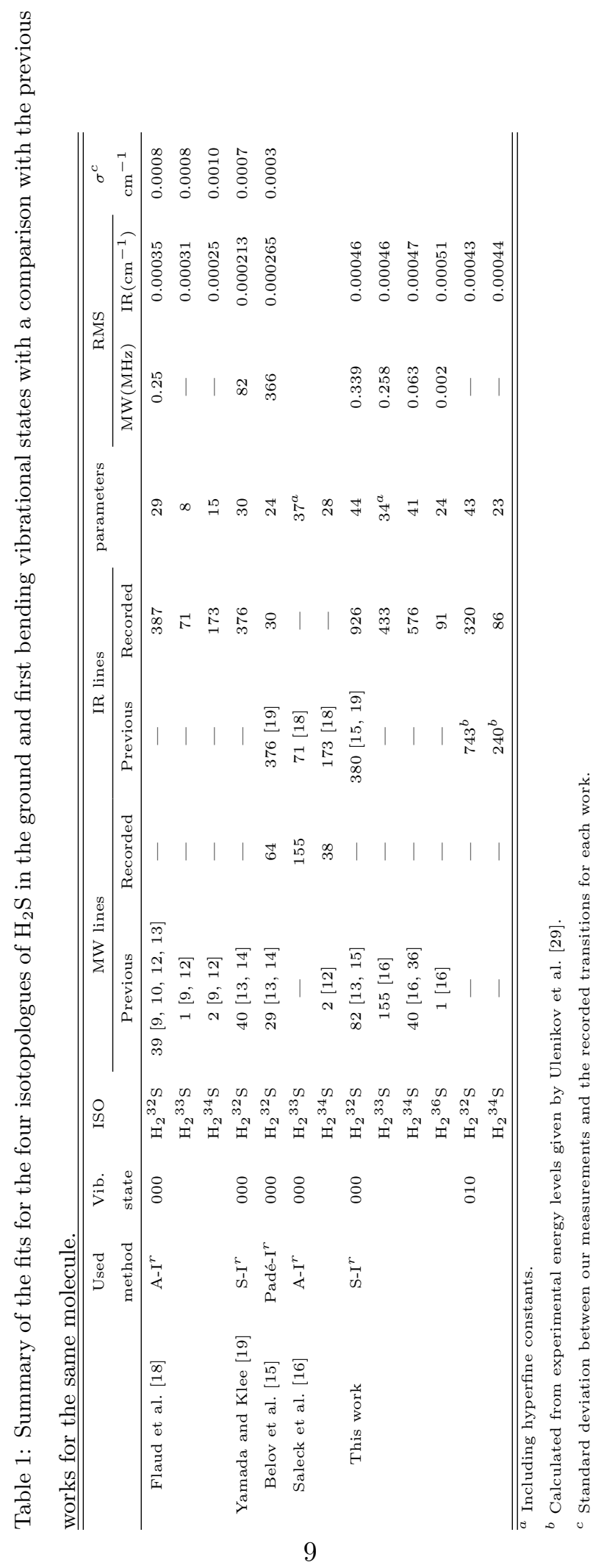


Table 2: Summary of available data for $\mathrm{H}_{2} \mathrm{~S}$ pure rotational transitions.

\begin{tabular}{|c|c|c|c|c|c|c|c|c|c|c|c|}
\hline \multirow{3}{*}{$\begin{array}{l}\text { Vib. } \\
\text { state }\end{array}$} & \multirow{3}{*}{$\begin{array}{l}\text { Data } \\
\text { source }\end{array}$} & & \multicolumn{4}{|c|}{ Number of lines } & \multicolumn{2}{|c|}{ Max. $J$} & \multicolumn{2}{|c|}{ Max. $K_{a}$} & \multirow{3}{*}{$\begin{array}{c}\sigma^{b} \\
\mathrm{~cm}^{-1}\end{array}$} \\
\hline & & & \multirow[t]{2}{*}{ Total } & \multicolumn{2}{|c|}{$\mathrm{M}$} & \multirow[t]{2}{*}{$\mathrm{P}$} & \multirow[t]{2}{*}{$\mathrm{M}$} & \multirow[t]{2}{*}{$\mathrm{P}$} & \multirow[t]{2}{*}{$\mathrm{M}$} & \multirow[t]{2}{*}{$\mathrm{P}$} & \\
\hline & & & & Microwave & Infrared & & & & & & \\
\hline \multirow[t]{11}{*}{000} & \multirow[t]{3}{*}{ HITRAN [18] } & $\mathrm{H}_{2}{ }^{32} \mathrm{~S}$ & 1540 & $39[9,10,12,13]$ & $387[18]$ & 1114 & 22 & 27 & 15 & 19 & 0.0062 \\
\hline & & $\mathrm{H}_{2}{ }^{33} \mathrm{~S}$ & 808 & $1[9,12]$ & $73[18]$ & 734 & 15 & 22 & 10 & 13 & 0.0008 \\
\hline & & $\mathrm{H}_{2}{ }^{34} \mathrm{~S}$ & 1048 & $2[9,12]$ & $173[18]$ & 873 & 18 & 24 & 12 & 15 & 0.0019 \\
\hline & \multirow[t]{3}{*}{ CDMS $[23,24]$} & $\mathrm{H}_{2}{ }^{32} \mathrm{~S}$ & 1501 & $82[11-13,15]$ & $441[15,18,19]$ & 978 & 22 & 25 & 15 & 19 & 0.0037 \\
\hline & & $\mathrm{H}_{2}{ }^{33} \mathrm{~S}$ & $4759^{a}$ & $155[16]$ & $73[18]$ & 4531 & 15 & 22 & 10 & 15 & - \\
\hline & & $\mathrm{H}_{2}{ }^{34} \mathrm{~S}$ & 990 & $40[12,16]$ & $173[18]$ & 777 & 18 & 24 & 12 & 16 & 0.0009 \\
\hline & JPL [22] & $\mathrm{H}_{2}{ }^{32} \mathrm{~S}$ & 1525 & $82[13,15,39]$ & $379[15,19]$ & 1064 & 16 & 21 & 13 & 18 & 0.0168 \\
\hline & \multirow[t]{4}{*}{ This work } & $\mathrm{H}_{2}{ }^{32} \mathrm{~S}$ & 2919 & $82[11-13,15]$ & 1306 & 1531 & 26 & 30 & 17 & 20 & \\
\hline & & $\mathrm{H}_{2}{ }^{33} \mathrm{~S}$ & 2471 & $155[16]$ & 433 & 2038 & 21 & 32 & 14 & 20 & \\
\hline & & $\mathrm{H}_{2}{ }^{34} \mathrm{~S}$ & 2554 & $40[12,16]$ & 576 & 1938 & 24 & 28 & 16 & 19 & \\
\hline & & $\mathrm{H}_{2}{ }^{36} \mathrm{~S}$ & 1004 & $1[16]$ & 91 & 912 & 15 & 17 & 11 & 13 & \\
\hline \multirow[t]{2}{*}{010} & \multirow[t]{2}{*}{ This work } & $\mathrm{H}_{2}{ }^{32} \mathrm{~S}$ & 1813 & & 1064 & 749 & 22 & 23 & 13 & 15 & \\
\hline & & $\mathrm{H}_{2}{ }^{34} \mathrm{~S}$ & 1011 & & 326 & 685 & 14 & 18 & 10 & 12 & \\
\hline
\end{tabular}

the available 40 millimete and sub-millimetre wave transition frequencies to test several forms of Watson's reduced Hamiltonian extended up to powers of $J^{10}$.

Ground state pure rotational transitions of $\mathrm{H}_{2}^{32} \mathrm{~S}$ were studied by Belov et al. [15] in 1995. They measured rotational transitions frequencies up to $36 \mathrm{~cm}^{-1}$ in Cologne and up to $85 \mathrm{~cm}^{-1}$ in Lille. The 84 measured lines were analysed together with the existing microwave and IR data recorded by Yamada and Klee [19] to test the Watson-type Hamiltonian and a Hamiltonian with a Padé formulation [40].

Yamada and Klee's measurements [19] were subsequently combined with the measurements by Helminger et al. [13], Belov et al. [15], Helminger et al. [39] to predict the $\mathrm{H}_{2}{ }^{32} \mathrm{~S}$ pure rotational lines which are in the JPL catalog [22] for $J$ up to 21 using $\mu=0.974 \mathrm{D}$ [10]. The data published in CDMS catalog was predicted for $\mathrm{H}_{2}{ }^{32} \mathrm{~S}$ up to $J=25, \mathrm{H}_{2}{ }^{33} \mathrm{~S}$ up to $J=22$, and $\mathrm{H}_{2}{ }^{34} \mathrm{~S}$ up to $J=24$ using the measurements from Refs. [11-13, 15, 18, 19] and $\mu=0.9783 \mathrm{D}$ [37].

The most accurate study of lines positions in the $\nu_{2}$ band of $\mathrm{H}_{2} \mathrm{~S}$ was performed by Ulenikov et al. [29]. In this work, lines were assigned to $\mathrm{H}_{2}{ }^{32} \mathrm{~S}$ and its isotopologues $\mathrm{H}_{2}{ }^{33} \mathrm{~S}$ and $\mathrm{H}_{2}{ }^{34} \mathrm{~S}$ with a resolution of $0.0020 \mathrm{~cm}^{-1}$. 226 upper state energy levels were obtained with $J \leq 17$ and 
Table 3: Parameters in $\mathrm{MHz}$ for the (000) vibrational state of $\mathrm{H}_{2}{ }^{32} \mathrm{~S}, \mathrm{H}_{2}{ }^{33} \mathrm{~S}_{2} \mathrm{H}_{2}{ }^{34} \mathrm{~S}$ and $\mathrm{H}_{2}{ }^{36} \mathrm{~S}$.

\begin{tabular}{|c|c|c|c|c|c|c|c|}
\hline & & Parameter & & $\mathrm{H}_{2}{ }^{32} \mathrm{~S}$ & $\mathrm{H}_{2}{ }^{33} \mathrm{~S}$ & $\mathrm{H}_{2}{ }^{34} \mathrm{~S}$ & $\mathrm{H}_{2}{ }^{36} \mathrm{~S}$ \\
\hline 1 & $10000^{a}$ & $A$ & & $310583.5798(106)$ & $310025.7737(197)$ & $309502.3997(103)$ & $308559.20(34)$ \\
\hline 2 & 20000 & $B$ & & $270367.6824(121)$ & $270367.1693(224)$ & $270366.9368(98)$ & $270354.74(174)$ \\
\hline 3 & 30000 & $C$ & & $141820.0415(69)$ & $141702.4070(174)$ & $141591.8242(93)$ & $141395.80(93)$ \\
\hline 4 & 200 & $\Delta_{J}$ & & $20.861771(261)$ & $20.87749(84)$ & $20.90496(56)$ & $20.6197(151)$ \\
\hline 5 & 1100 & $\Delta_{J K}$ & & $-76.23237(64)$ & $-76.33674(232)$ & $-76.48005(180)$ & $-73.937(98)$ \\
\hline 6 & 2000 & $\Delta_{K}$ & & $117.72636(68)$ & $117.58223(196)$ & $117.49020(147)$ & $115.559(126)$ \\
\hline 7 & 40100 & $\delta_{J}$ & & $8.865995(99)$ & $8.863831(281)$ & $8.866950(141)$ & $8.5716(195)$ \\
\hline 8 & 50000 & $\delta_{K}$ & & $-0.641960(33)$ & $-0.654477(112)$ & $-0.666993(74)$ & $-0.7067(38)$ \\
\hline 9 & 300 & $H_{J}$ & & $0.01022690(312)$ & $0.0100421(84)$ & $0.0102278(111)$ & \\
\hline 10 & 1200 & $H_{J J K}$ & & $-0.0903531(127)$ & $-0.089668(58)$ & $-0.091210(55)$ & \\
\hline 11 & 2100 & $H_{J K K}$ & & $0.155866(35)$ & $0.154950(126)$ & $0.157519(49)$ & $0.0576(33)$ \\
\hline 12 & 3000 & $H_{K}$ & & $-0.0338364(300)$ & $-0.033831(117)$ & $-0.035149(42)$ & \\
\hline 13 & 40200 & $h_{J}$ & $10^{-03}$ & $2.88144(151)$ & $2.8209(39)$ & $2.8646(35)$ & $-3.639(194)$ \\
\hline 14 & 50100 & $h_{J K}$ & $10^{-03}$ & $-0.96339(71)$ & $-0.97261(229)$ & $-0.98017(188)$ & $-1.1850(286)$ \\
\hline 15 & 60000 & $h_{K}$ & $10^{-03}$ & $1.24685(33)$ & $1.25103(125)$ & $1.26596(65)$ & $1.1179(110)$ \\
\hline 16 & 400 & $L_{J}$ & $10^{-06}$ & $-5.6700(186)$ & $-4.0663(291)$ & $-5.551(71)$ & $103.98(288)$ \\
\hline 17 & 1300 & $L_{J J J K}$ & $10^{-03}$ & $0.072865(181)$ & $0.058824(298)$ & $0.07417(49)$ & $-0.9742(215)$ \\
\hline 18 & 2200 & $L_{J J K K}$ & $10^{-03}$ & $-0.22325(78)$ & $-0.18567(146)$ & $-0.20564(95)$ & $1.173(42)$ \\
\hline 19 & 3100 & $L_{J K K K}$ & $10^{-03}$ & $0.27447(96)$ & $0.23823(310)$ & $0.23350(146)$ & $-0.5454(194)$ \\
\hline 20 & 4000 & $L_{K}$ & $10^{-03}$ & $-0.16145(53)$ & $-0.14806(233)$ & $-0.13911(68)$ & \\
\hline 21 & 40300 & $l_{J}$ & $10^{-06}$ & $-1.0205(81)$ & $-0.6487(138)$ & $-1.0517(280)$ & $57.95(177)$ \\
\hline 22 & 50200 & $l_{J J K}$ & $10^{-06}$ & $-0.2743(37)$ & $-0.2523(93)$ & $-0.2579(98)$ & \\
\hline 23 & 60100 & $l_{J k k}$ & $10^{-06}$ & $-1.7256(50)$ & $-1.5518(71)$ & $-1.6312(56)$ & \\
\hline 24 & 70000 & $l_{K}$ & $10^{-06}$ & $0.39780(137)$ & $0.4483(58)$ & $0.4605(37)$ & \\
\hline 25 & 500 & $M_{J}$ & $10^{-09}$ & $4.801(60)$ & & $3.712(147)$ & $-364.4(167)$ \\
\hline 26 & 1400 & $M_{J J J J K}$ & $10^{-06}$ & $-0.06825(128)$ & & $-0.04173(149)$ & $3.847(148)$ \\
\hline 27 & 2300 & $M_{J J J K K}$ & $10^{-06}$ & $0.2466(58)$ & & & $-3.981(205)$ \\
\hline 28 & 3200 & $M_{J J K K K}$ & $10^{-06}$ & $-0.4541(77)$ & $-0.0936(105)$ & & $1.756(130)$ \\
\hline 29 & 4100 & $M_{J K K K K}$ & $10^{-06}$ & $0.4151(40)$ & $0.1808(240)$ & $0.2908(127)$ & \\
\hline 30 & 5000 & $M_{K}$ & $10^{-06}$ & $-0.09827(255)$ & $-0.0538(151)$ & $-0.1882(95)$ & \\
\hline 31 & 40400 & $p_{J}$ & $10^{-09}$ & $0.8269(141)$ & & $0.941(64)$ & $-187.8(86)$ \\
\hline 32 & 60200 & $p_{J J K K}$ & $10^{-09}$ & $0.7954(275)$ & & & \\
\hline 33 & 70100 & $p_{J K K K}$ & $10^{-09}$ & $-0.6732(104)$ & $-0.7882(203)$ & $-1.0281(192)$ & $4.074(302)$ \\
\hline 34 & 80000 & $p_{K}$ & $10^{-09}$ & $0.33763(256)$ & $0.3172(123)$ & $0.2162(38)$ & \\
\hline 35 & 600 & $S_{J}$ & $10^{-09}$ & $-0.003664(90)$ & & & \\
\hline 36 & 1500 & $S_{J K}$ & $10^{-09}$ & $0.07339(253)$ & & $-0.02754(260)$ & $-2.857(188)$ \\
\hline 37 & 2400 & $S_{J J K}$ & $10^{-09}$ & $-0.2464(111)$ & & $0.3880(168)$ & \\
\hline 38 & 3300 & $S_{K K J}$ & $10^{-09}$ & $0.2604(134)$ & & $-0.954(39)$ & \\
\hline 39 & 5100 & $S_{K J}$ & $10^{-09}$ & $-0.1150(63)$ & & $0.2930(165)$ & \\
\hline 40 & 50400 & $s_{J J K}$ & $10^{-12}$ & $0.9302(190)$ & $0.5108(216)$ & $0.571(60)$ & \\
\hline 41 & 60300 & $s_{K K J J}$ & $10^{-12}$ & $-0.509(48)$ & & $1.175(57)$ & \\
\hline 42 & 70200 & $s_{K K J}$ & $10^{-12}$ & $0.2140(203)$ & & $0.7967(281)$ & \\
\hline 43 & 80100 & $s_{K J}$ & $10^{-12}$ & $-0.4382(77)$ & $-0.549(34)$ & & \\
\hline 44 & 90000 & $s_{K}$ & $10^{-12}$ & $0.02109(147)$ & & $0.0954(46)$ & \\
\hline 45 & 3400 & $T_{K J}$ & $10^{-12}$ & & & $1.205(70)$ & \\
\hline \multirow[t]{5}{*}{46} & 3500 & $U_{K J}$ & $10^{-15}$ & & & $-1.633(65)$ & \\
\hline & 110010000 & $X_{a a 1}$ & & & $-32.841(78)$ & & \\
\hline & 110020000 & $X_{b b 1}$ & & & $-8.635(98)$ & & \\
\hline & 10020000 & $C_{b b 1}$ & & & $0.0281(77)$ & & \\
\hline & & $\sigma_{\mathrm{rms}}$ & & 0.93487 & 0.93345 & 0.95080 & 1.01830 \\
\hline
\end{tabular}


Table 4: Parameters in $\mathrm{MHz}$ for the (010) vibrational state of $\mathrm{H}_{2}{ }^{32} \mathrm{~S}$ and $\mathrm{H}_{2}{ }^{34} \mathrm{~S}$.

\begin{tabular}{|c|c|c|c|c|c|c|}
\hline & & \multicolumn{2}{|l|}{ Parameter } & $\mathrm{H}_{2}{ }^{32} \mathrm{~S}$ & $\mathrm{H}_{2}{ }^{34} \mathrm{~S}$ & \\
\hline 1 & $10000^{a}$ & \multicolumn{2}{|l|}{$A$} & $321448.00(92)$ & $320320.70(93)$ & \\
\hline 2 & 20000 & \multicolumn{2}{|l|}{$B$} & $276539.09(59)$ & $276527.92(58)$ & \\
\hline 3 & 30000 & \multicolumn{2}{|l|}{$C$} & $139968.49(45)$ & $139745.45(33)$ & \\
\hline 4 & 200 & \multicolumn{2}{|l|}{$\Delta_{J}$} & $22.7889(120)$ & $22.9990(92)$ & \\
\hline 5 & 1100 & \multicolumn{2}{|l|}{$\Delta_{J K}$} & $-83.055(36)$ & $-84.175(41)$ & \\
\hline 6 & 2000 & \multicolumn{2}{|l|}{$\Delta_{K}$} & $138.498(49)$ & $138.140(56)$ & \\
\hline 7 & 40100 & \multicolumn{2}{|l|}{$\delta_{J}$} & $10.3437(43)$ & $10.4004(46)$ & \\
\hline 8 & 50000 & \multicolumn{2}{|l|}{$\delta_{K}$} & $-0.12951(55)$ & $-0.14990(69)$ & \\
\hline 9 & 300 & \multicolumn{2}{|l|}{$H_{J}$} & $0.008815(134)$ & $0.011775(75)$ & \\
\hline 10 & 1200 & \multicolumn{2}{|l|}{$H_{J J K}$} & $-0.09011(63)$ & $-0.10151(42)$ & \\
\hline 11 & 2100 & \multicolumn{2}{|l|}{$H_{J K K}$} & $0.19188(124)$ & $0.16602(110)$ & \\
\hline 12 & 3000 & \multicolumn{2}{|l|}{$H_{K}$} & $-0.02368(114)$ & $-0.01116(144)$ & \\
\hline 13 & 40200 & $h_{J}$ & $10^{-03}$ & $2.551(58)$ & $3.670(36)$ & \\
\hline 14 & 60000 & $h_{K}$ & $10^{-03}$ & $1.7950(59)$ & $1.5654(50)$ & \\
\hline 15 & 400 & $L_{J}$ & $10^{-03}$ & $0.02418(66)$ & & \\
\hline 16 & 1300 & $L_{J J J K}$ & $10^{-03}$ & $-0.0569(49)$ & & \\
\hline 17 & 2200 & $L_{J J K K}$ & $10^{-03}$ & $-0.4467(94)$ & & \\
\hline 18 & 3100 & $L_{J K K K}$ & $10^{-03}$ & $0.5360(251)$ & & \\
\hline 19 & 4000 & $L_{K}$ & $10^{-03}$ & $-0.4698(183)$ & & \\
\hline 20 & 40300 & $l_{J}$ & $10^{-06}$ & $9.21(32)$ & & \\
\hline 21 & 50200 & $l_{J J K}$ & $10^{-06}$ & $-8.560(127)$ & $-4.340(79)$ & \\
\hline 22 & 60100 & $l_{J k k}$ & $10^{-06}$ & $-5.399(79)$ & & Pickett's program CALPGM notations [35] \\
\hline 23 & 500 & $M_{J}$ & $10^{-06}$ & $-0.10405(155)$ & & \\
\hline 24 & 1400 & $M_{J J J J K}$ & $10^{-06}$ & $0.3766(132)$ & & \\
\hline 25 & 2300 & $M_{J J J K K}$ & $10^{-06}$ & $1.625(71)$ & & \\
\hline 26 & 3200 & $M_{J J K K K}$ & $10^{-06}$ & $-1.798(196)$ & $1.930(140)$ & \\
\hline 27 & 5000 & $M_{K}$ & $10^{-06}$ & $2.674(109)$ & $-4.338(228)$ & \\
\hline 28 & 40400 & $p_{J}$ & $10^{-06}$ & $-0.02665(64)$ & & \\
\hline 29 & 50300 & $p_{J J J K}$ & $10^{-06}$ & $0.04927(104)$ & & \\
\hline 30 & 60200 & $p_{J J K K}$ & $10^{-06}$ & $0.02644(45)$ & & \\
\hline 31 & 70100 & $p_{J K K K}$ & $10^{-06}$ & $0.004057(58)$ & $0.01145(71)$ & \\
\hline 32 & 80000 & $p_{K}$ & $10^{-09}$ & $0.4954(111)$ & $-4.28(37)$ & \\
\hline 33 & 600 & $S_{J}$ & $10^{-09}$ & $0.10009(282)$ & & \\
\hline 34 & 2400 & $S_{J J K}$ & $10^{-09}$ & $-5.056(245)$ & & \\
\hline 35 & 3300 & $S_{K K J}$ & $10^{-09}$ & $5.98(52)$ & $-9.99(59)$ & \\
\hline 36 & 6000 & $S_{K}$ & $10^{-09}$ & $-0.000010520(279)$ & $0.00002790(127)$ & \\
\hline 37 & 50400 & $s_{J J K}$ & $10^{-09}$ & $-0.10802(238)$ & & \\
\hline 38 & 60300 & $s_{K K J J}$ & $10^{-09}$ & $-0.06970(114)$ & $-0.07184(225)$ & \\
\hline 39 & 70200 & $s_{K K J}$ & $10^{-09}$ & $-0.014413(295)$ & $-0.1020(49)$ & \\
\hline 40 & 90100 & & $10^{-15}$ & $7.904(239)$ & & \\
\hline 41 & 100000 & & $10^{-15}$ & $5.208(237)$ & & \\
\hline 42 & 7100 & & $10^{-12}$ & $-0.07457(239)$ & & \\
\hline 43 & 8000 & & $10^{-12}$ & $0.12992(202)$ & & \\
\hline & & $\sigma_{\mathrm{rms}}$ & & 0.85759 & 0.87911 & \\
\hline
\end{tabular}


$K_{a} \leq 13$ for $\mathrm{H}_{2}{ }^{32} \mathrm{~S}$. 181 of these energy levels up to $J \leq 17$ and $K_{a} \leq 10$ were fitted with a standard deviation of $9.96 \times 10^{-2} \mathrm{~cm}^{-1}$. For $\mathrm{H}_{2}{ }^{34} \mathrm{~S}, 126$ energy levels with $J \leq 14$ and $K_{a} \leq 10$ were obtained, 80 of them up to $J \leq 12$ and $K_{a} \leq 7$ were used to fit the constants for the $v_{2}=1$ vibrational state of this isotopologue. Ulenikov et al. [29] used the ground state energies for the three isotopologues from Ref. [18].

\subsection{Rotational transitions in the ground vibrational state}

As can be seen from Table 1, we were able to extend significantly the number of the experimental infrared lines for all of four isotopologues of $\mathrm{H}_{2} \mathrm{~S}$ considered. For instance, for the transitions within the ground vibrational state of $\mathrm{H}_{2}{ }^{32} \mathrm{~S}$, we recorded 926 lines, while only 387 lines from the same spectral region were reported by Flaud et al. [18]. Our spectrum contains lines with $J$ up to 26 and $K_{a}$ up to 17 , which also significantly extends the coverage of the energy levels probed, see Table1. This table also shows standard deviations between our measured line positions and the previously measured line positions. Our analysis suggests that while we get very good agreement with the previous measurements, there are problems with the predicted line positions tabulated in the databases, see Table 2. Figure 4 illustrates some of these errors in the prediction of the lines positions in the HITRAN and CDMS databases; Table 6 summarises these problems. Figures 5 and 6 give general idea about the accuracy of the line positions available in these databases and that from our fit.

Rotational transitions of the $\mathrm{H}_{2}{ }^{36} \mathrm{~S}$ isotopologue in its ground vibrational state are detected in this work up to $J=15$ and $K_{a}=11$. Over 50 lines were identified and assigned manually by extrapolation method mentioned above. As a result, 91 lines were assigned as $\mathrm{H}_{2}{ }^{36} \mathrm{~S}$ lines with a root mean square error of $0.00051 \mathrm{~cm}^{-1}$.

Saleck et al. [16] published three recorded microwave lines as $\mathrm{H}_{2}{ }^{36} \mathrm{~S}$ rotational transitions. From these lines, only the transitions $2_{0,2}-1_{1,1}$ line at $686766.635 \mathrm{MHz}$. could be added to our fit without destroying it. These three transitions are listed in Table 5 and compared to the predicted line positions resulting from our fit. 
Table 5: Three $\mathrm{H}_{2}{ }^{36} \mathrm{~S}$ rotational transitions published by Saleck et al. [16] and their counterparts calculated in this work. The numbers in parentheses next to Saleck et al. and This work transition values are the experimental uncertainty and the fitting estimated error, respectively. $\Delta$ is the differece between the transitions in the two works.

\begin{tabular}{cccr}
\hline \hline$J_{K_{a}, K_{c}}^{\prime}-J_{K_{a}, K_{c}}^{\prime \prime}$ & Saleck et al. $(\mathrm{MHz})$ & This work $(\mathrm{MHz})$ & $\Delta(\mathrm{MHz})$ \\
\hline $3_{3,1}-3_{2,2}$ & $559250.950(0.100)$ & $559796(27)$ & -546 \\
$4_{4,1}-4_{3,2}$ & $636677.520(0.100)$ & $637643(37)$ & -966 \\
$2_{0,2}-1_{1,1}$ & $686766.635(0.100)^{a}$ & $686772(24)$ & -6 \\
\hline \hline \multicolumn{4}{c}{${ }^{a}$ Line is included in our fit. }
\end{tabular}

\subsection{Rotational transitions in the bending vibrational state $v_{2}=1$ of $\mathrm{H}_{2}{ }^{32} \mathrm{~S}$ and $\mathrm{H}_{2}{ }^{34} \mathrm{~S}$}

We were able to assign initially 214 pure rotational transitions associated with the vibrational state $v_{2}=1$ of $\mathrm{H}_{2}{ }^{32} \mathrm{~S}$ covering energy levels up to $J=20$ and $K_{a}=14$ using the variationally calculated line list. Then 181 experimental energy levels up to $J \leq 17$ and $K_{a} \leq 10$ from Ref. [29] were used to calculate 759 rotational transitions in the first excited bending state for $\mathrm{H}_{2}{ }^{32} \mathrm{~S} .559$ of these calculated transitions are in the region $45-360 \mathrm{~cm}^{-1}$. The calculations were performed using the combination differences method. As a result, 216 transitions could be matched to transitions in our spectrum with the standard deviation of $0.0004 \mathrm{~cm}^{-1}$. Eight lines were found to have much higher errors in their calculated positions (all close to $0.3 \mathrm{~cm}^{-1}$ ). All of these lines belong to the energy levels $12_{2,11}$ and $12_{1,11}$, and all the calculated transitions involving these energy levels showed the same problem. We suspect this is a typographical problem in the corresponding table of Ref. [29]. However these transitions were excluded from the fit and these lines are tabulated in the supplementary material. Our spectrum contains 104 transitions that cannot be calculated from Ulenikov et al.'s experimental energy levels. These new recorded transitions have quantum numbers up to $J=22$ and $K_{a}=13$. Figure 7 shows the accuracy of the fit performed in this work for $\mathrm{H}_{2}{ }^{32} \mathrm{~S}$ rotational spectrum in the $v_{2}=1$ state as well as the calculated rotational transitions using the experimental energy levels of Ulenikov et al. [29] and the variationally calculated line list. 


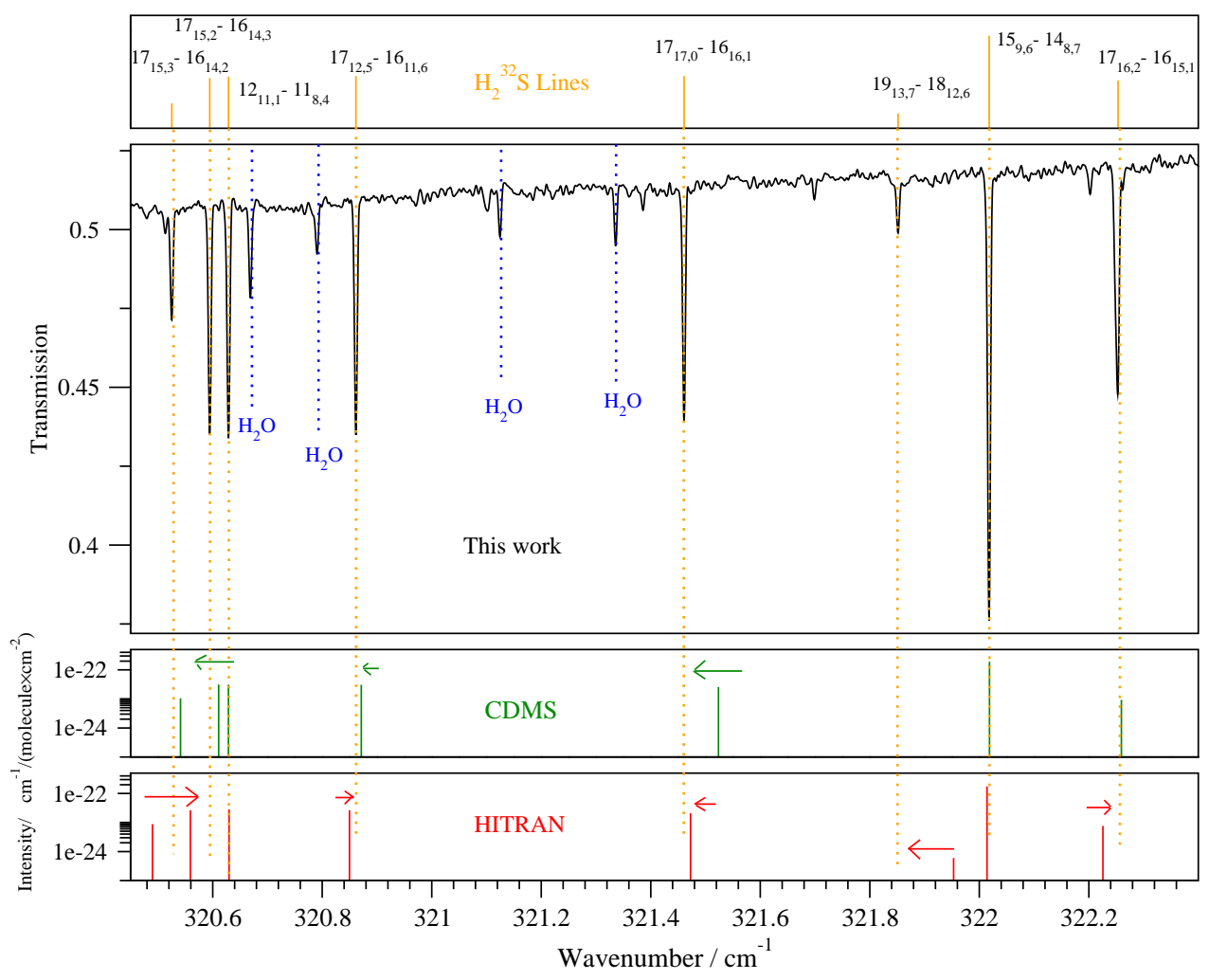

Figure 4: A portion of the absorption spectrum of $\mathrm{H}_{2} \mathrm{~S}$ recorded at SOLEIL, showing the errors in the line positions predicted in HITRAN and CDMS databases.

For $\mathrm{H}_{2}^{34} \mathrm{~S}, 240$ rotational transitions up to $J=12$ and $K_{a}=7$ were calculated using the 80 experimental energy levels published by Ulenikov et al. [29]. 177 lines of these calculated transitions are in the region $45-360 \mathrm{~cm}^{-1}$. 42 lines could be assigned in our spectrum using these calculated transitions for $J \leq 10$ and $K_{a} \leq 6$. After fitting the effective Hamiltonian's constants, 44 extra lines were assigned up to $J=14$ and $K_{a}=10$. Figure 7 shows the accuracy of the fit for $\mathrm{H}_{2}{ }^{34} \mathrm{~S}$ rotational spectrum in the $v_{2}=1$ state and the calculated rotational transitions using the experimental energy levels of Ulenikov et al. [29].

Figure 2 shows a portion of the assigned spectrum which includes transitions for the four isotopologues of $\mathrm{H}_{2} \mathrm{~S}$ with the same quantum numbers and some pure rotational $v_{2}=1$ transitions of $\mathrm{H}_{2}{ }^{32} \mathrm{~S}$ and $\mathrm{H}_{2}{ }^{34} \mathrm{~S}$. 
Table 6: Summary of the differences in the predicted line positions, in $\mathrm{cm}^{-1}$, in different databases compared to the measured line positions of this work.

\begin{tabular}{|c|c|c|c|c|c|c|}
\hline \multirow{2}{*}{$\begin{array}{l}\text { Vib. state } \\
\text { transition }\end{array}$} & \multirow[t]{2}{*}{ ISO } & \multirow[t]{2}{*}{ Data source } & \multirow{2}{*}{$\begin{array}{c}\text { Max. absolute } \\
\text { error }\end{array}$} & \multicolumn{2}{|c|}{ error $>0.001 \mathrm{~cm}^{-1}$} & \multirow{2}{*}{$\begin{array}{l}\text { Number of lines } \\
\text { errors }>0.001 \mathrm{~cm}^{-1}\end{array}$} \\
\hline & & & & Min. $J$ & Min. $K_{a}$ & \\
\hline \multirow[t]{11}{*}{ 000-000 } & $\mathrm{H}_{2}{ }^{32} \mathrm{~S}$ & HITRAN & 0.0687 & 3 & 1 & 213 \\
\hline & & CDMS & 0.0626 & 3 & 2 & 139 \\
\hline & & JPL & 0.2141 & 3 & 2 & 238 \\
\hline & & This work & 0.0025 & 4 & 0 & 105 \\
\hline & & Line list [30] & 0.0848 & 3 & 3 & 780 \\
\hline & $\mathrm{H}_{2}{ }^{33} \mathrm{~S}$ & HITRAN & 0.0056 & 2 & 0 & 124 \\
\hline & & This work & 0.0023 & 6 & 1 & 30 \\
\hline & $\mathrm{H}_{2}{ }^{34} \mathrm{~S}$ & HITRAN & 0.0202 & 6 & 1 & 62 \\
\hline & & CDMS & 0.0087 & 6 & 1 & 40 \\
\hline & & This work & 0.0022 & 6 & 1 & 35 \\
\hline & $\mathrm{H}_{2}{ }^{36} \mathrm{~S}$ & This work & 0.0014 & 10 & 1 & 3 \\
\hline \multirow[t]{3}{*}{ 010-010 } & $\mathrm{H}_{2}{ }^{32} \mathrm{~S}$ & This work & 0.0023 & 9 & 2 & 18 \\
\hline & & Line list [30] & 0.3695 & 2 & 1 & 203 \\
\hline & $\mathrm{H}_{2}{ }^{34} \mathrm{~S}$ & This work & 0.0032 & 7 & 0 & 17 \\
\hline
\end{tabular}



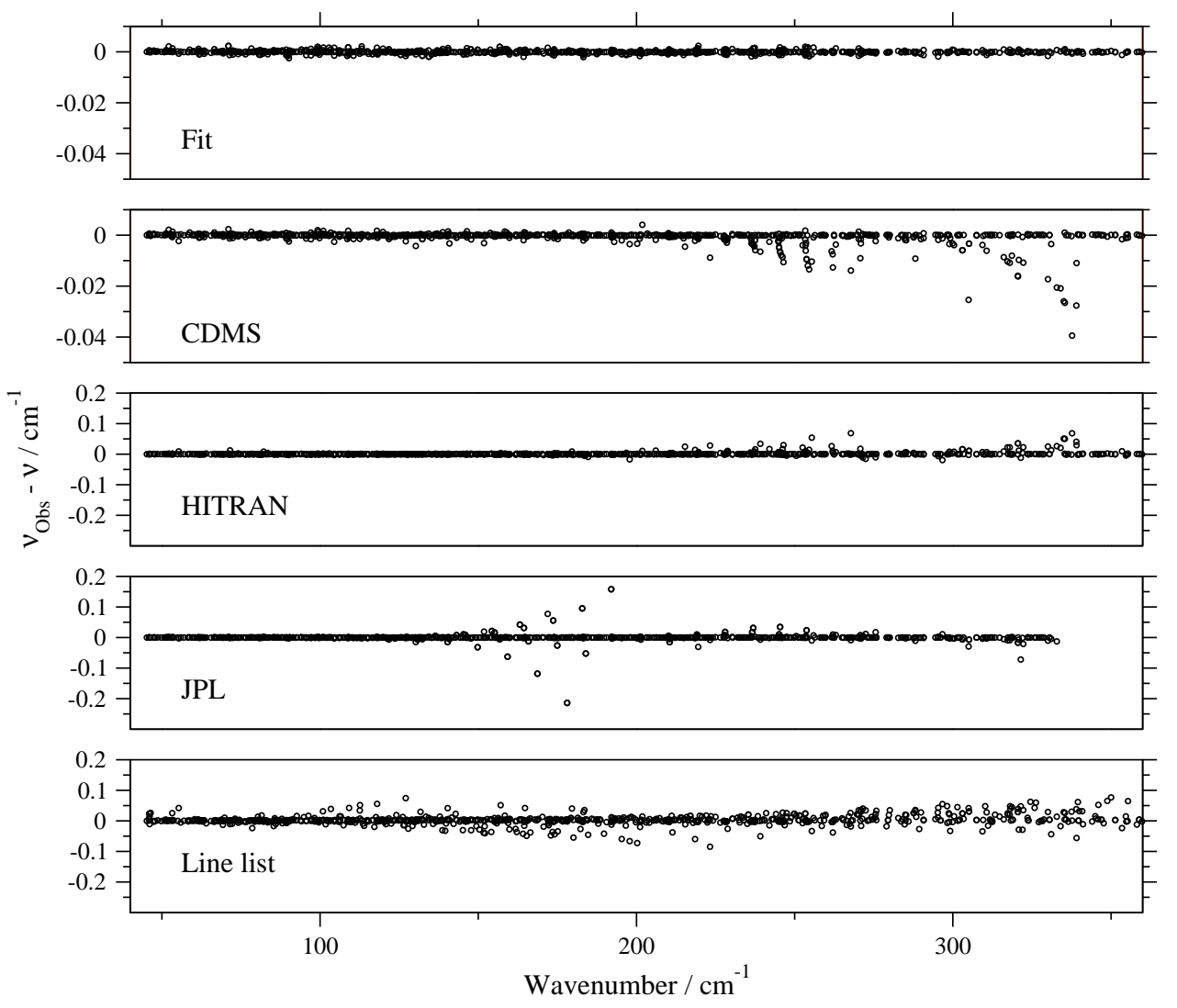

Figure 5: Accuracy of the ground vibrational state rotational transitions of $\mathrm{H}_{2}{ }^{32} \mathrm{~S}$ in different databases compared to our measurements. $\nu_{\mathrm{Obs}}-\nu$ represents the deviations of the line positions measured here from that of CDMS [23], HITRAN [21], JPL [22] and variational calculations [30]. Note the magnified scale for our fit and CDMS.

\section{Conclusions}

More than 1300 new lines in the pure rotational band of the absorption spectrum for $\mathrm{H}_{2}{ }^{32} \mathrm{~S}$, $\mathrm{H}_{2}{ }^{33} \mathrm{~S}, \mathrm{H}_{2}{ }^{34} \mathrm{~S}$, and $\mathrm{H}_{2}{ }^{36} \mathrm{~S}$ are detected and assigned in the ground vibrational state as well as in the first excited bending vibrational state for $\mathrm{H}_{2}{ }^{32} \mathrm{~S}$ and $\mathrm{H}_{2}{ }^{34} \mathrm{~S}$. Using these newly detected lines, the effective rotational constants for the four isotopologues of $\mathrm{H}_{2} \mathrm{~S}$ in the two vibrational states have been fitted. Problems in predicted lines positions from CDMS, and JPL databases made on the basis previous studies were identified. Our new data has been submitted for inclusion in the 2012 update of the HITRAN database [41]. 


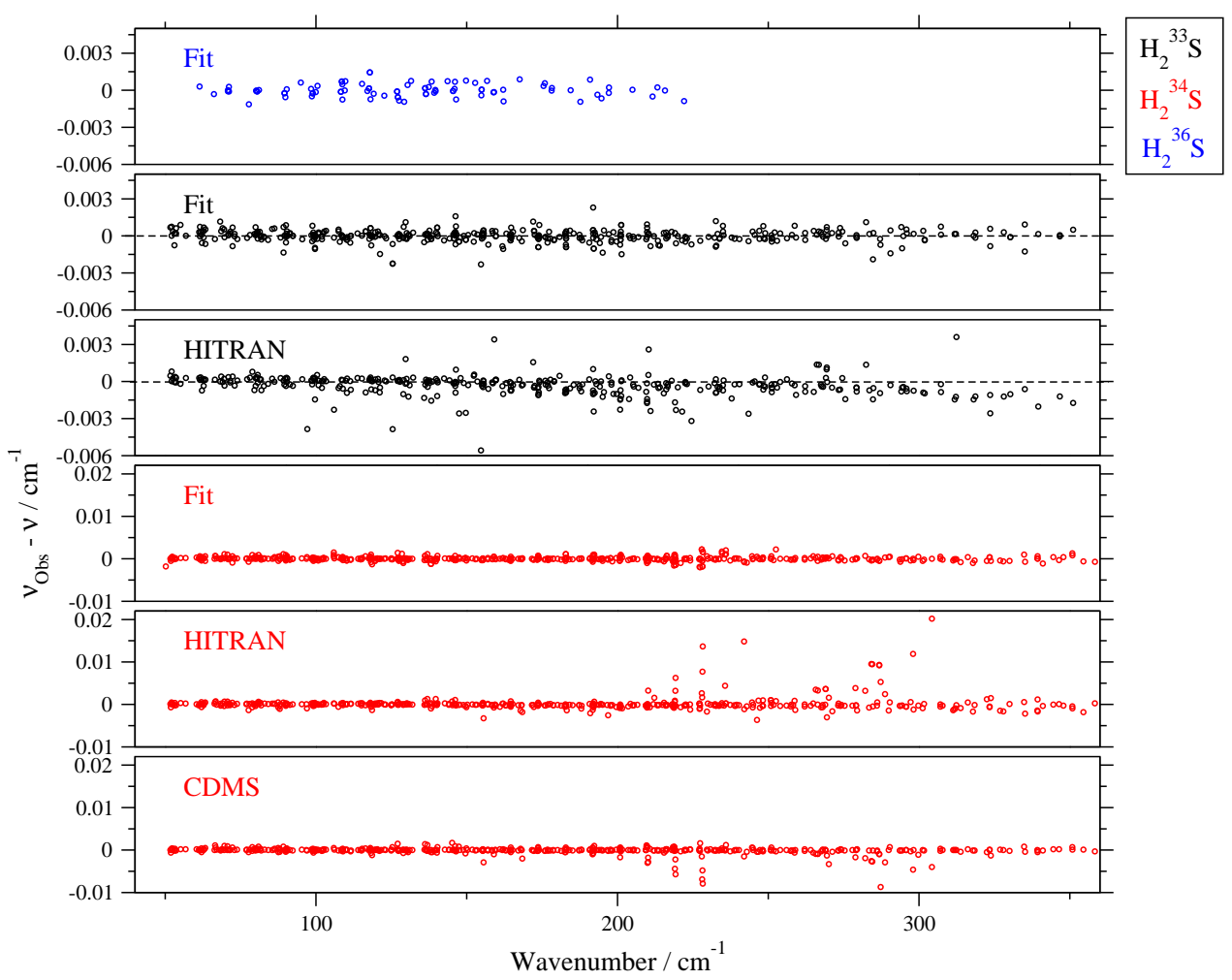

Figure 6: Accuracy of the ground vibrational state rotational transitions of $\mathrm{H}_{2}{ }^{33} \mathrm{~S}$ and $\mathrm{H}_{2}{ }^{34} \mathrm{~S}$ in our fit and HITRAN [21] compared to our measurements. $\nu_{\mathrm{Obs}}-\nu$ are given as our observed frequency minus our fit and HITRAN [21]. Note the plots for $\mathrm{H}_{2}{ }^{34} \mathrm{~S}$ are on a different vertical scale.

\section{Acknowledgements}

We thank Olga Naumenko and an anonymous referee for helpful comments on our manuscript, and Oleg Polyansky for helpful discussions during the course of this work. Ala'a Azzam thanks the University of Jordan for financial support. This work is partially supported by ERC Advanced Investigator Project 267219.

\section{References}

[1] G. Hoshyaripour, M. Hort, B. Langmann, How does the hot core of a volcanic plume control the sulfur speciation in volcanic emission?, Geochem. Geophys. Geosys. 13 (2012) Q07004. 


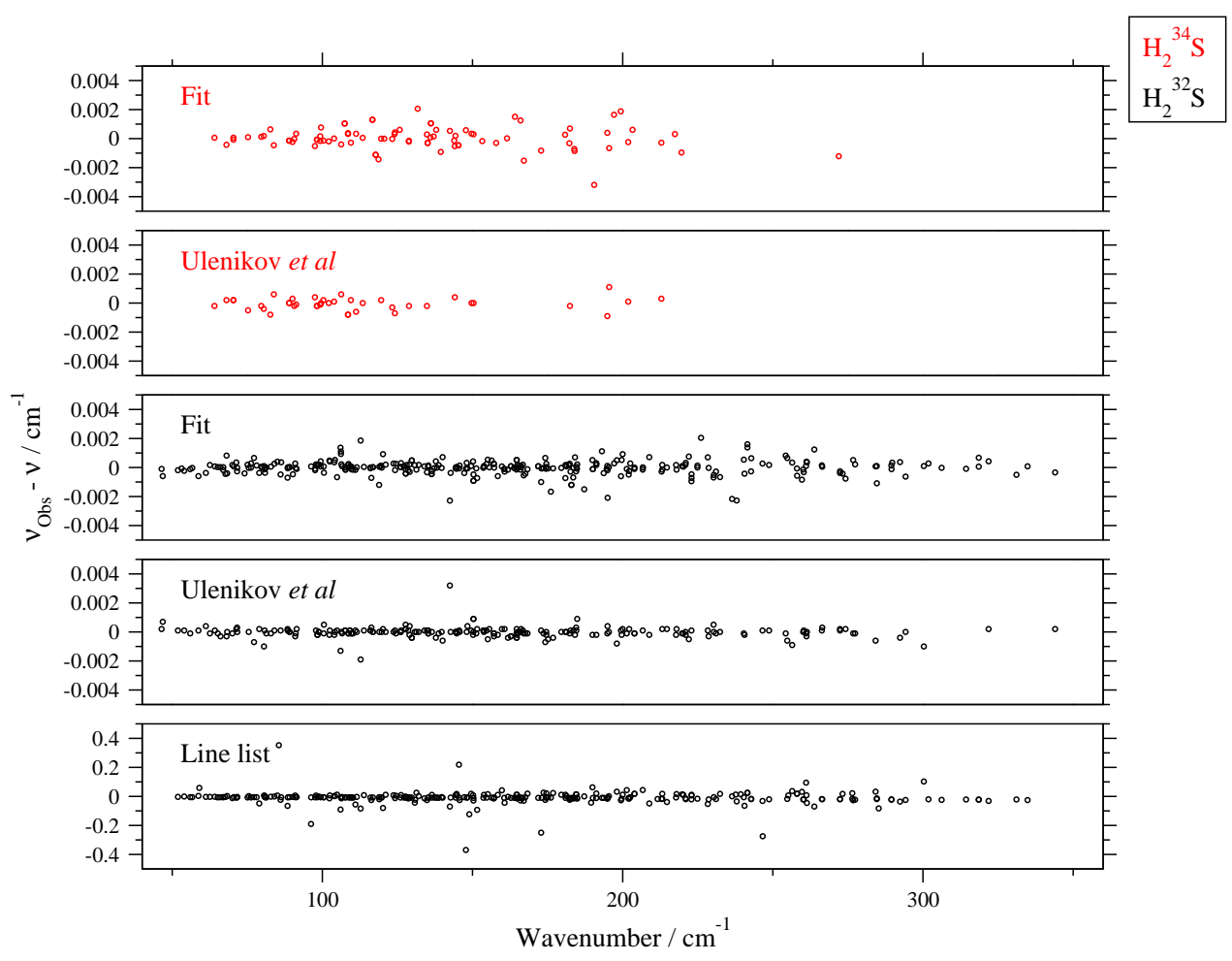

Figure 7: Accuracy of the first bending vibrational state rotational transitions of $\mathrm{H}_{2}{ }^{32} \mathrm{~S}$ and $\mathrm{H}_{2}{ }^{34} \mathrm{~S}$ in our fit, and the transitions calculated from the experimental energy levels published by Ulenikov et al. [29] compared to our measurements. Also the variational calculations [30] compared to our measurements for $\mathrm{H}_{2}{ }^{32} \mathrm{~S} . \nu_{\mathrm{Obs}}-\nu$ given as our observed frequency minus our fit, Ulenikov et al.'s transitions, and the variational calculations. Note the reduced scale for the line list.

[2] F. Llavador Colomer, H. Espinos Morato, E. Mantilla Iglesias, Estimation of hydrogen sulfide emission rates at several wastewater treatment plants through experimental concentration measurements and dispersion modeling, J. Air Waste Management Assoc. 62 (2012) 758-766.

[3] C. Visscher, K. Lodders, B. Fegley, Jr., Atmospheric chemistry in giant planets, brown dwarfs, and low-mass dwarf stars. II. Sulfur and phosphorus, Astron. Astrophys. 648 (2006) 1181-1195.

[4] K. Zahnle, M. S. Marley, R. S. Freedman, K. Lodders, J. J. Fortney, Atmospheric sulfur photochemistry on hot jupiters, Astrophys. J. 701 (2009) L20-L24.

[5] P. Thaddeus, R. W. Wilson, M. L. Kutner, K. B. Jefferts, A. A. Penzias, Interstellar hydrogen sulfide, Astrophys. J. 176 (1972) L73.

[6] R. Aladro, S. Martin, J. Martin-Pintado, R. Mauersberger, C. Henkel, B. Ocana Flaquer, M. A. AmoBaladron, A $\lambda=1.3 \mathrm{~mm}$ and $2 \mathrm{~mm}$ molecular line survey towards $\mathrm{m} \mathrm{82,} \mathrm{Astron.} \mathrm{Astrophys.} 535$ (2011) 
A84.

[7] V. Wakelam, A. Castets, C. Ceccarelli, B. Lefloch, E. Caux, L. Pagani, Sulphur-bearing species in the star forming region 11689n, Astron. Astrophys. 413 (2004) 609-622.

[8] Justtanont, K., Khouri, T., Maercker, M., Alcolea, J., Decin, L., Olofsson, H., Schöier, F. L., Bujarrabal, V., Marston, A. P., Teyssier, D., Cernicharo, J., Dominik, C., de Koter, A., Melnick, G., Menten, K. M., Neufeld, D., Planesas, P., Schmidt, M., Szczerba, R., Waters, R., Herschel/hifi observations of o-rich agb stars: molecular inventory, Astron. Astrophys. 537 (2012) A144.

[9] C. A. Burrus, JR., W. Gordy, One-to-two millimeter wave spectroscopy. II. $\mathrm{H}_{2}$ S, Phys. Rev. 92 (1953) $274-277$.

[10] C. Huiszoon, A. Dymanus, Magnetic hyperfine structure the rotational spectrum of $\mathrm{H}_{2} \mathrm{~S}$, Phys. Lett. 21 (1966) 164-166.

[11] R. E. Cupp, R. A. Keikpf, J. J. Gallagher, Hyperfine structure in the millimeter spectrum of hydrogen sulfide electric spectroscopy on asymmetric-top molecules, Phys. Rev. 171 (1968) 60-69.

[12] C. Huiszoon, A high resolution spectrometer for the shorter millimeter wavelength region, Rev. Sci. Instrum. 42 (1971) 477-481.

[13] P. Helminger, R. L. Cook, F. C. De Lucia, Microwave spectrum and centrifugal distortion effects of $\mathrm{H}_{2} \mathrm{~S}, \mathrm{~J}$. Chem. Phys. 56 (1972) 4581-4584.

[14] A. V. Burenin, T. M. Fevralskikh, A. A. Melnikov, S. M. Shapin, Microwave spectrum of the hydrogen sulfide molecule $\mathrm{H}_{2}{ }^{32} \mathrm{~S}$ in the ground state, J. Mol. Spectrosc. 109 (1985) 1-7.

[15] S. P. Belov, K. M. T. Yamada, G. Winnewisser, L. Poteau, R. Bocquet, J. Demaison, O. Polyansky, M. Y. Tretyakov, Terahertz rotational spectrum of $\mathrm{H}_{2} \mathrm{~S}$, J. Mol. Spectrosc. 173 (1995) 380-390.

[16] A. H. Saleck, M. Tanimoto, S. P. Belov, T. Klaus, G. Winnewisser, Millimeter- and submillimeter-wave rotational spectra of rare hydrogen sulfide isotopomers, J. Mol. Spectrosc. 171 (1995) 481493.

[17] R. E. Miller, G. E. Leroi, T. M. Hard, Analysis of the pure rotational absorption spectra of hydrogen sulfide and deuterium sulfide, J. Chem. Phys. 50 (1969) 677-684.

[18] J.-M. Flaud, C. Camy-Peyret, J. W. C. Johns, The far-infrared spectrum of hydrogen-sulfide - the (000) rotational-constants of $\mathrm{H}_{2}{ }^{32} \mathrm{~S}, \mathrm{H}_{2}{ }^{33} \mathrm{~S}$ and $\mathrm{H}_{2}{ }^{34} \mathrm{~S}$, Can. J. Phys. 61 (1983) 1462-1473.

[19] K. M. T. Yamada, S. Klee, Pure rotational spectrum of $\mathrm{H}_{2} \mathrm{~S}$ in the far-infrared region measured by ftir spectroscopy, J. Mol. Spectrosc. 166 (1994) 395-405.

[20] L. S. Rothman, D. Jacquemart, A. Barbe, D. C. Benner, M. Birk, L. R. Brown, M. R. Carleer, C. Chackerian, K. Chance, L. H. Coudert, V. Dana, V. M. Devi, J.-M. Flaud, R. R. Gamache, A. Goldman, J.-M. Hartmann, K. W. Jucks, A. G. Maki, J.-Y. Mandin, S. T. Massie, J. Orphal, A. Perrin, C. P. Rinsland, M. A. H. Smith, J. Tennyson, R. N. Tolchenov, R. A. Toth, J. Vander Auwera, P. Varanasi, G. Wagner, The HITRAN 2004 molecular spectroscopic database, J. Quant. Spectrosc. Radiat. Transf. 96 (2005) 139-204. 
[21] L. S. Rothman, I. E. Gordon, A. Barbe, D. C. Benner, P. F. Bernath, M. Birk, V. Boudon, L. R. Brown, A. Campargue, J. P. Champion, K. Chance, L. H. Coudert, V. Dana, V. M. Devi, S. Fally, J. M. Flaud, R. R. Gamache, A. Goldman, D. Jacquemart, I. Kleiner, N. Lacome, W. J. Lafferty, J. Y. Mandin, S. T. Massie, S. N. Mikhailenko, C. E. Miller, N. Moazzen-Ahmadi, O. V. Naumenko, A. V. Nikitin, J. Orphal, V. I. Perevalov, A. Perrin, A. Predoi-Cross, C. P. Rinsland, M. Rotger, M. Simeckova, M. A. H. Smith, K. Sung, S. A. Tashkun, J. Tennyson, R. A. Toth, A. C. Vandaele, J. Vander Auwera, The HITRAN 2008 molecular spectroscopic database, J. Quant. Spectrosc. Radiat. Transf. 110 (2009) 533-572.

[22] H. M. Pickett, R. L. Poynter, E. A. Cohen, M. L. Delitsky, J. C. Pearson, H. S. P. Muller, Submillimeter, millimeter, and microwave spectral line catalog, J. Quant. Spectrosc. Radiat. Transf. 60 (1998) 883-890.

[23] H. S. P. Müller, S. Thorwirth, D. A. Roth, G. Winnewisser, The cologne database for molecular spectroscopy, cdms, Astron. Astrophys. 370 (2001) L49-L52.

[24] H. S. P. Müller, F. Schlöder, J. Stutzki, G. Winnewisser, The cologne database for molecular spectroscopy, cdms: a useful tool for astronomers and spectroscopists, J. Molec. Struct. (THEOCHEM) 742 (2005) 215-227.

[25] I. N. Kozin, P. Jensen, Fourfold clusters of rotational energy levels for $\mathrm{H}_{2} \mathrm{~S}$ studied with a potential energy surface derived from experiment, J. Mol. Spectrosc. 163 (1994) 483-509.

[26] W. C. Lane, T. H. Edwards, J. R. Gillis, F. S. Bonomo, F. J. Murcray, Analysis of $\nu_{2}$ of $\mathrm{H}_{2}$ S, J. Mol. Spectrosc. 95 (1982) 365-380.

[27] L. L. Strow, Line strength measurements using diode laser: the $\nu_{2}$ band of $\mathrm{H}_{2} \mathrm{~S}$, J. Quant. Spectrosc. Radiat. Transf. 29 (1983) 395-406.

[28] W. C. Lane, T. H. E. J. R. Gillis, F. S. Bonomo, F. J. Murcray, Analysis of $\nu_{2}$ of $\mathrm{H}_{2}{ }^{33} \mathrm{~S}_{\text {and }} \mathrm{H}_{2}{ }^{34} \mathrm{~S}, \mathrm{~J}$. Mol. Spectrosc. 111 (1985) 320-326.

[29] O. N. Ulenikov, A. B. Malikova, M. Koivusaari, S. Alanko, R. Anttila, High resolution vibrational.rotational spectrum of $\mathrm{H}_{2} \mathrm{~S}$ in the region of the $\nu_{2}$ fundamental band, J. Mol. Spectrosc. 176 (1996) 229-235.

[30] A. A. A. Azzam, S. N. Yurckenko, J. Tennyson, Exomol molecular linelists: Iii a linelist for the hydrogen sulphide molecule, Mon. Not. R. Astr. Soc. (2013) (to be submitted).

[31] J.-B. Brubach, L. Manceron, M. Rouzières, O. Pirali, D. Balcon, F. Kwabia-Tchana, V. Boudon, M. Tudorie, T. Huet, A. Cuisset, P. Roy, Performance of the AILES THz-Infrared beamline at SOLEIL for High resolution spectroscopy, in: WIRMS 2009, volume 1214 of AIP Conference Proceedings, 2010, pp. 81-84.

[32] F. Matsushima, H. Odashima, T. Iwasaki, S. Tsunekawa, K. Takagi, Frequency-measurement of pure rotational transitions of $\mathrm{H}_{2} \mathrm{O}$ from 0.5 to 5 THz, J. Mol. Struct. 352 (1995) 371-378.

[33] V. M. Horneman, R. Anttila, S. Alanko, J. Pietila, Transferring calibration from CO2 laser lines to far infrared water lines with the aid of the $\nu_{2}$ band of OCS and the $\nu_{2}, \nu_{1}-\nu_{2}$, and $\nu_{1}+\nu_{2}$ bands of ${ }^{13} \mathrm{CS}_{2}$ : Molecular constants of ${ }^{13} \mathrm{CS}_{2}$, J. Mol. Spectrosc. 234 (2005) 238-254.

[34] J. Tennyson, M. A. Kostin, P. Barletta, G. J. Harris, O. L. Polyansky, J. Ramanlal, N. F. Zobov, DVR3D: 
a program suite for the calculation of rotation-vibration spectra of triatomic molecules, Comput. Phys. Commun. 163 (2004) 85-116.

[35] H. M. Pickett, The fitting and prediction of vibration-rotation spectra with spin interactions, J. Mol. Spectrosc. 148 (1991) 371-377.

[36] C. Huiszoon, A. Dymanus, Stark effect of millimeter wave transitions, I. hydrogen sulfide., Physica 31 (1965) 1049-1052.

[37] R. Viswanathan, T. R. Dyke, Electric dipole moments and nuclear hyperfine interactions for $\mathrm{H}_{2} \mathrm{~S}$, HDS, and $\mathrm{D}_{2}$ S, J. Mol. Spectrosc. 103 (1984) 231-239.

[38] M. Šimečková, D. Jacquemart, L. S. Rothman, R. R. Gamache, A. Goldman, Einstein A coefficients and statistical weights for molecular absorption transitions in the HITRAN database, J. Quant. Spectrosc. Radiat. Transf. 98 (2006) 130-155.

[39] P. Helminger, F. C. De Lucia, W. H. Kirchhoff, Microwave spectra of molecules of astrophysical interest iv. hydrogen sulfide, J. Phys. Chem. Ref. Data 2 (1973) 215-223.

[40] O. L. Polyansky, One-dimensional approximation of the effective rotational hamiltonian of the ground-state of the water molecule, J. Mol. Spectrosc. 112 (1985) 79-87.

[41] L. S. Rothman, et al, The hitran database: 2012 edition, J. Quant. Spectrosc. Radiat. Transf. (2013) (this issue). 